\title{
Sánchez Rodríguez, V. (2018). La soprano María Barrientos y sus epístolas de juventud (1905-1906). Málaga: UMA Editorial, 198 pp. ISBN: 978-84-17449-35-
} 3.

La obra que la autora Virginia Sánchez Rodríguez daba a luz en el mes de octubre de 2018 supone una relevante contribución en la recuperación de la participación femenina en un ámbito historiográfico y musical dominado tradicionalmente por el hombre. Galardonadas con el Accésit del XXVIII Premio Internacional Victoria Kent 2018, sus páginas recogen la figura de un nombre fundamental en el panorama de la interpretación vocal de nuestro país y con amplio reconocimiento internacional, la de la soprano española María Barrientos (1884-1946), mostrando ya en el título el plato fuerte de la obra: unas misivas manuscritas propiedad de la cantante y que detallaremos más adelante.

Sin embargo, aunque pudiera parecer un recopilatorio de la empresa de la artista para su reivindicación, no trata de destacar tanto su labor musical como el valor de su ruptura con convencionalismos de una sociedad patriarcal que, a pesar de los avances feministas de la época en el mundo occidental, seguía empeñada en relegar a la mujer bajo la creencia de su inferioridad.

No podemos negar que el texto está escrito con mimo por las adecuadas manos de la musicóloga, pianista, profesora de la Universidad de Castilla-La Mancha (UCLM) y miembro del Centro de Investigación y Documentación Musical (CIDoM) y que cuenta con el Premio de investigación a la Mejor Tesis Doctoral de la Fundación de la Sociedad General de Autores y Editores (SGAE) 2013, el Premio de Investigación "Rosario Valpuesta" de la Diputación de Sevilla (2015), la beca de investigación etnográfica Ángel Carril del Instituto de las Identidades de la Diputación de Salamanca (2016) y la beca de investigación en Folklore de CIOFF (2018), entre otros galardones y reconocimiento. Y es que una de las líneas de investigación de Virginia no es otra que la que comprende el estudio de mujeres a lo largo de la historia dentro del mundo de la música y del cine, así como el análisis de los roles de género representado en las artes audiovisuales.

De este modo, trata de seguir sumando en la visibilización de la mujer en la música $y$, en especial, de la intérprete, marcada por un rol limitado y secundario debido a la hegemonía masculina e históricamente a la sombra de la composición. En este caso persigue este destino con una compañía inmejorable, pues además de su innegable talento, María Barrientos también atesoraba un carácter inconformista que la hacían cuestionar ciertas convenciones sociales y adoptar una personalidad independiente y activa en sus decisiones. 
Sin embargo, el retiro de la destacada cantante de ópera entre 1907 y 1911 estuvo marcado, según las fuentes, por lo personal y la supeditación marital, aspectos que confrontan directamente con sus condiciones. Esto, unido a la desinformación y la falta de datos en torno a la figura de la catalana a pesar de su distendida y exitosa carrera, motivó la hipótesis que supone el motor de la presente obra y que no busca otra cosa que vislumbrar las intenciones reales que motivaron la interrupción de su actividad, razón por la que se centra en los años 1905 y 1906 de su vida, principalmente, como etapa concreta de estudio.

En este sentido, los objetivos que la autora persigue están claramente dibujados ya en el primer bloque introductorio del libro. Fines que entroncan con aproximar la participación femenina en materia de interpretación, ahondar en la dimensión personal y profesional de María Barrientos como parte de la realidad artística de la época, profundizar en aspectos poco manidos en la historiografía como su juventud, manera de pensar y sus interacciones y descubrir los motivos de su retiro en el período de tiempo comentado.

Y sobre todo es en esta última misión en donde encontramos un mayúsculo atractivo porque sí, se trata de una investigación académica en toda regla, pero la presentación de sus ingredientes la plantea de tal modo que hace al lector implicado partícipe de cada descubrimiento. Esto se debe a una mantenida intriga por la resolución de la cuestión no desvelada hasta el final y la facilitación del material objeto de análisis expuesto íntegro para deleite del curioso consumidor. Se tratan de nueve cartas manuscritas por María Barrientos a José Bilbao, administrador del Teatro Real de Madrid, custodiadas dentro del Fondo José Subirá conservadas en la Biblioteca de Cataluña y que la autora pone a nuestra disposición para saborearlas e iniciar nuestra exploración a la par.

Como no podía ser de otra manera, las referencias empleadas no resultan un punto flaco de la obra, ofreciendo un trabajo bien documentado y cuyas fuentes la propia describe, citando además las más relevantes, el porqué de su importancia y detallando su acceso. Éstas corresponden, presumiblemente, a una ardua tarea de localización y revisión bibliográfica que peina áreas hemerográficas contemporáneas nacionales e internacionales y literarias dentro de la historia de la música, y que incluyen libros y volúmenes únicos. Pero, como decíamos, uno de los mayores encantos de este documento reside en las fuentes primarias y esas epístolas de belleza incalculable de las que disponemos, por vez primera, publicadas.

Con una metodología y una estructura piramidal invertida que se preocupa de dejar claras para facilitar el mapa organizativo mental del escrito al lector, la obra desarrolla a partir de aquí el meollo en tres partes definidas amén de unas conclusiones que recogen y reflexionan con tono profesional, crítico y personal acerca de lo extraído en aquellas. Eso sí, no sin antes ofrecer un estado de la cuestión caracterizado por el difícil acceso y la escasez de obras y referencias poco vagas que aludan al legado de la mujer, reflejo del interés tradicional por la labor del género opuesto y que evidencia la necesidad de actuación, por otro lado, posible, como dan parte las acciones iniciadas por la musicología feminista en la creación de obras e instituciones. 
Así, el primer capítulo, "Música y mujer" (páginas 30-62), hace las veces de repaso historiográfico al papel de la mujer en el plano de la música contemporánea. Acompañado, como el resto del texto, de pies de página generosos y aclaratorios y de extractos de volúmenes y referencias variadas, nos plantea un cuadro breve, pero necesario, centrado en la etapa referida y que esboza con atino ilustrando compositoras e intérpretes de cada momento, divagando en autoras y nuevas músicas femeninas surgidas por los devenires sociales hasta llegar al contexto peninsular final que desemboca en la cantante. Alertando entonces de la cantidad de artistas mujeres que exigen profundización, prepara el terreno para abordar su específica parte del cometido con nuestra protagonista.

"María Barrientos" (páginas 63-111) da nombre a un segundo capítulo decidido a ocupar el vacío en la literatura musical con respecto a su figura. Para ello recoge los pasos de la soprano marcando decididamente el camino recorrido desde su juventud, incluyendo su labor interpretativa, docente y los diversos premios que obtuvo. Un trayecto no exento de incongruencias en diversas fuentes secundarias que la autora se encarga de advertir y aclarar en notas que aprovecha además para introducir apreciaciones y suposiciones personales, al margen siempre de lo narrado. No da puntada sin hilo en un episodio cuyo discurso encontramos ampliamente documentado y apoyado con material fotográfico, programas de actuaciones de la época, fragmentos y críticas de revistas y entrevistas traducidas acompañadas de un texto original que es de agradecer.

En "Las epístolas de juventud de una diva (1905-1906)" (páginas 112-176), el que completa el trío de capítulos central, adivinamos dos secciones. La primera obedece a un ejercicio de transcripción y publicación inédita hasta la fecha, revelando y poniendo a nuestra disposición cada una de las nueve epístolas, a las que se les ha aplicado, en una muestra de esfuerzo voluntarioso, la ortografía actual, pero respetado la puntuación original. La lectura de estas, que destilan buena simpatía y respeto, nos trasladan de lleno al momento y nos inmiscuyen en la acción, pudiendo así degustar de primera mano una fuente de este calibre.

La segunda parte de este episodio lo dedica la doctora Sánchez Rodríguez al análisis de la colección, diferenciando el estudio en los ámbitos profesional y personal de la artista, tras referenciar en primera instancia la valoración previa de las cartas por parte del entonces secretario del Instituto Español de Musicología y académico de la Real Academia de Bellas Artes de San Fernando José Subirá. En el examen hallamos un valioso legado en cuanto a los artistas y empresarios del momento que en las cartas aparecen y de quienes muestra una relación precisa y sucinta, pero cuidada y con todo lujo de detalles. Un apartado nada desdeñable para conocer las relaciones con la protagonista y edificar el conglomerado social del panorama musical del momento.

Pero esto sólo es un retal, pues los datos y conclusiones se abalanzan y precipitan en un torbellino de ideas que exprime los recursos. Las actuaciones de Barrientos que aparecen en las misivas, ahora comentadas y apoyadas en fracciones literales de críticas y periódicos del extranjero, dan paso al terreno menos musical, donde las enfermedades que padeció en este período y el trato que la prensa les dio copan los preliminares. 


\section{RESEÑAS DE LIBROS}

Rescatando los puntos significantes de cada carta, las fechas y lugares de escritura se suceden, de cuyo estilo y contenido extrae deducciones, descansando sobre extractos textuales, de acuerdo con el reflejo de posturas de relación social propias de los convencionalismos de la época e inferencias acerca de una moral religiosa de la cantante que no refutaba su papel activo en relaciones. Y es que, como atestiguan las conclusiones de manera previa a la reivindicación de la investigación feminista en este ámbito, la idea de retirada ya era barajada por María Barrientos antes de su matrimonio con Jorge Keen, respondiendo de esta forma a un deseo personal.

La profesionalidad y empeño en la causa de la doctora Sánchez Rodríguez quedan patentes en un documento de lectura amena y agradable, nada tediosa. Un escrito con una naturaleza didáctica y aires de archivo de investigación propia del contexto formativo que, sin embargo, a veces nos sorprenderá creyendo estar leyendo una novela narrativa de las bien contadas, de esas que te atrapan. La presentación de una hipótesis que amenaza romper creencias en torno a la figura de María Barrientos fruto de la especulación embaucadora de las convenciones de género y la exposición de las nueve cartas íntegras e inéditas a modo de prueba, hacen que la lectura, fresca y dinámica, adquiera un tono detectivesco que involucra de lleno a un lector que saborea y sigue las pistas para conocer, junto a la autora, el desenlace de unos acontecimientos que completan una acertada contribución en un acercamiento incesante y directo al necesario reconocimiento igualitario.

Javier Benito Blanco

Universidad de Castilla-La Mancha

ORCID iD: http://orcid.org/0000-0003-2576-6857 